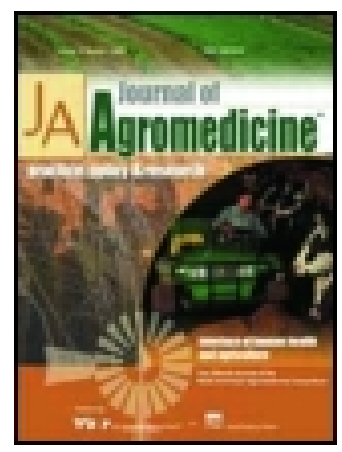

Journal of Agromedicine

\title{
Predictors of attitudes towards non-technical skills in farming
}

\section{Amy Irwin \& Jill Poots}

To cite this article: Amy Irwin \& Jill Poots (2017): Predictors of attitudes towards non-technical skills in farming, Journal of Agromedicine, DOI: 10.1080/1059924X.2017.1384775

To link to this article: http://dx.doi.org/10.1080/1059924X.2017.1384775

View supplementary material $\asymp$

Accepted author version posted online: 27
Sep 2017.

Submit your article to this journal $₫$

山 Article views: 5

Q View related articles ¿ك

View Crossmark data $[\pi$ 


\title{
Predictors of Attitudes towards Non-Technical Skills in Farming
}

Amy Irwin and Jill Poots

Industrial Psychology Research Centre, School of Psychology, University of Aberdeen, Scotland, AB24 2UB.

CONTACT Dr. Amy Irwin, School of Psychology, University of Aberdeen, William Guild Building, Aberdeen, AB24 2UB, Scotland, UK. Electronic mail: $\underline{\text { a.irwin@abdn.ac.uk }}$

Funding: This research was funded by the University of Aberdeen.

Disclosure: No financial interest or benefit has arisen from this research.

Acknowledgements: The authors would like to thank all of the farm participants for giving up their time to take part in this study.

\begin{abstract}
Objectives: Farming is a high risk sector with up to 170,000 worldwide fatalities reported per year; it is therefore vital to identify methods of mitigating the dangers of this industry. Research within high-risk industries, such as aviation, shipping, and agriculture, has identified the importance of non-technical skills (NTS) in maintaining effective, safe performance and reducing error and injury. However, there is a lack of research evaluating factors that may contribute to NTS attitudes and behaviors. As a first step to address this literature gap the current study evaluated a range of individual and environmental factors as potential predictors of attitudes towards NTS in agriculture.
\end{abstract}


Method: A sample of 170 farmers from within the United Kingdom and Ireland were surveyed using an online questionnaire. The questionnaire included measures of personality, stress, attitudes towards safety (safety climate, motivation, and risk), environmental stressors (workload, work-life imbalance) and non-technical skills (team and lone worker).

Results: Attitudes towards safety climate, compliance and motivation showed a significant association with both team-based and lone worker NTS. Conscientiousness correlated positively with the majority of the NTS elements. Multiple regression analysis indicated neuroticism and conscientiousness demonstrated capacity to predict NTS attitudes. Concerns about costs and equipment, attitudes towards safety climate and safety motivation were also found to be significant predictors of NTS attitudes.

Conclusion: The results indicate the utility of individual characteristics, and environmental factors when predicting farming NTS attitudes. As a result these elements could be important when evaluating engagement with NTS, and developing NTS training initiatives in agriculture.

Keywords: Non-technical skills; safety; farming; attitudes; personality

\section{Introduction}

Between 2014 and 2015 in the United Kingdom (UK) there were 36 recorded fatalities in agriculture. This included reports of a worker suffering asphyxiation in a grain bin and a farm employee dying in a tele-handler collision. ${ }^{1}$ These accidents highlight the dangers inherent to agriculture, a high risk industrial sector that accounts for approximately one in five of all fatal injuries to UK workers and an estimated 170,000 annual farm worker fatalities worldwide. ${ }^{2}$

The hazards that can have an impact on farm worker safety are well known, including machinery, ${ }^{3}$ farm animals, ${ }^{4}$ and working at heights. ${ }^{5}$ Less known is the link between poor attitudes towards safety and injury rates in agriculture. ${ }^{6}$ Stress, related to job strain or 
stressors, has also been reported as a risk factor. ${ }^{7,8}$ Accident reports suggest that failures in non-technical skills (NTS), such as an awareness of the environment and communication, might be associated with injuries. ${ }^{9}$ For example, in the case of the asphyxiated worker, the report indicates that the workers were unaware of the consequences of certain actions. ${ }^{1}$

Research suggests that self-reported attitudes towards safety in the workplace may predict the likelihood of a worker engaging in safe ${ }^{6,10}$ or risky behaviours. ${ }^{11}$ Similarly, assessment of attitudes towards non-technical skills should give some insight into performance of NTS. ${ }^{12}$ To facilitate NTS, it is important to investigate factors that might influence NTS attitudes. This type of research has not yet been conducted with NTS attitudes as the focus, despite research evaluating predictors of general safety attitudes. ${ }^{13}$ Therefore, the current study sought to assess the utility of personality, safety attitudes, stress, and environmental factors as predictors of team-based and lone worker NTS in agriculture. By improving our understanding of factors influencing NTS attitudes this type of research should contribute to enhancing farmer NTS and safety.

\section{Non-technical skills}

Non-technical skills have been defined as the social (leadership, teamwork, and communication) and cognitive skills (decision-making, situation awareness, and task management) necessary for safe and effective task performance. ${ }^{14}$ Within industry a link between failures in NTS and adverse events has been established; for example, poor teamwork has been linked to offshore drilling incidents, ${ }^{15}$ and NTS failures have been identified as causal factors in the destruction of Deepwater Horizon. ${ }^{16}$ Much of this research has focused on identifying NTS across job roles and industries to develop skill taxonomies for training and assessment purposes (see development of $\operatorname{ANTS}^{17}$ and SPLINTS ${ }^{18}$ ).

This research recently expanded into agriculture through an exploratory interview study, leading to the identification of NTS suitable for farming. ${ }^{19}$ The study indicated that 
NTS were important for farming safety, and there were two sub-sets of NTS: team-based and lone worker NTS. Consideration of the skills utilized when alone is particularly important as farming is traditionally considered an independent occupation. ${ }^{20}$

Prior to the Irwin and Poots ${ }^{19}$ paper, there had not been a study directly addressing NTS in farming. However, elements of previous research are indicative of the importance of such skills in farming. For example, a Health, Safety and Executive report ${ }^{9}$ indicates the importance of task management by suggesting that farmers can cope with stress by engaging in planning and preparation prior to beginning a task. Farmar-Bowers and Lane ${ }^{21}$ report that farmers engage in several contexts dependent decision-making strategies. A study assessing injuries within dairy farms reports that farmers consider the awareness of the handler to be an important element in avoiding injury. ${ }^{22}$

\section{Predictors of farmer safety}

Neal and Griffin ${ }^{23}$ proposed a model of safety that links safety motivation, safety knowledge, and safety climate to safety performance. In their model safety performance encompasses working with others, adhering to procedures and taking initiative. ${ }^{23}$ Based on that model, which appears to include elements of NTS in safety performance, and to identify factors that might influence NTS attitudes, predictors of general farm safety performance were investigated. Glasscock and colleagues ${ }^{8}$ examined working conditions, perceived work stressors, stress, and safety behaviors as potential predictors of accident and injury rates in farmers. The results indicated that high levels of perceived stressors were associated with low levels of reported safety behaviors and predicted an increased risk of injury. Similarly, in a study examining dairy farmers, job strain, age, and experience were found to be positively correlated with duration spent in close proximity to the cattle, and in turn with the risk of injury. ${ }^{24}$ Hagel et al. ${ }^{25}$ also reported a link between economic worry and accident risk. The 
authors suggested that financial issues might prevent investment in safety equipment and may also result in farm operators working longer hours, thus raising the risk of accident through fatigue. $^{25}$

Research assessing farm worker handling of cattle identified working alone and having no immediate escape route as two factors that were linked to risk of injury. ${ }^{22}$ A study with Finnish farmers identified farm size (larger farms associated with greater risk), working alone, and male gender as significant risk factors. ${ }^{26}$ A more recent study reported that safety motivation was associated with safety behaviour. ${ }^{27}$

\section{Personality and workplace safety}

There are several proposed links between personality and attitudes that align with elements of NTS. Extraversion is a trait usually associated with social confidence, assertiveness, enthusiasm, and a focus on excitement. ${ }^{28}$ Linked to this, researchers have suggested extraverts are likely to engage in risk taking behaviors, show less vigilance, and exhibit unsafe behaviors at work. ${ }^{29,30}$ Agreeableness, linked with empathy and working well with others, ${ }^{30}$ has been shown to be positively associated with safety compliance ${ }^{31}$ and general safety attitudes. ${ }^{13}$ Conscientiousness, a trait linked to being careful and thorough, particularly when managing tasks or making decisions, ${ }^{32}$ has been negatively associated with unsafe behaviours. ${ }^{33}$ Neuroticism, a trait linked with anxiousness and insecurity, was reported as negatively correlating with safety compliance. ${ }^{10}$ It has also been suggested that neurotic individuals are likely to be easily distracted and struggle to deal with stress. ${ }^{13,30}$ Finally, a meta-analysis reported that agreeableness and conscientiousness were positively associated with safety behaviors. In contrast neuroticism and extraversion were negatively associated with safety behaviours. ${ }^{34}$ 


\section{Study aims and hypotheses}

Despite the importance of NTS in enhancing safety across multiple industries, no research, to our knowledge, has addressed potential predictors of NTS. Such predictors, at both the individual and environment level, may impact NTS attitudes and, therefore, NTS behaviors. The current exploratory study aimed to examine potential predictors (individual traits, attitudes towards safety and the presence of environmental stressors) of NTS attitudes in farming in order to begin to address this literature gap.

\section{Hypotheses:}

1. Individual traits (personality, level of experience, level of stress) will have a significant association with attitudes towards team-based and lone non-technical skills. Specifically the following relationships are expected:

1.1 Conscientiousness and farm experience should have a positive association with attitudes towards task management, situation awareness and decision-making.

1.2 Agreeableness should be positively associated with attitudes towards leadership, teamwork and communication.

1.3 Extraversion should be positively associated with teamwork, and negatively associated with situation awareness, task management and decision-making.

1.4 Neuroticism and stress are expected to have a negative association with situation awareness, teamwork, decision-making and task management.

2. Attitudes towards safety and risk on the farm (safety climate, safety motivation, safety behavior) will have a positive association with attitudes towards team-based and lone nontechnical skills. In contrast, risk tolerance should have a negative association with nontechnical skills.

3. Concern about environmental stressors (workload, costs, equipment and work-life imbalance) will have a significant positive association with non-technical skills. 
4. Attitudes towards non-technical skills should differ across gender, level of training and farm type.

\section{Method}

\section{Participants}

A total of 170 participants (136 male, 32 female, 2 not stated; age range $18-82$ years) were recruited from UK and Ireland within a 2-month period (approximate 30\% response rate based on views of online posts and emails sent). The participants were recruited from several different types of farm: Dairy farm $(n=28)$; Beef cattle $(n=15)$; Sheep $(n=26)$; Pigs $(n=$ $3)$; Poultry $(n=2)$ and mixed animal farms $(n=29)$. There were crop producers $(n=25)$ and mixed animal and crop farms $(n=44)$. All the participants considered farming to be their primary occupation.

\section{Questionnaire}

Section one: Demographic information, including age, training, years of experience farming, type of farm and size of farm. No data on location was collected.

Section two: Five-item version of the General Health Questionnaire. ${ }^{35}$ This scale was designed to assess current levels of stress and wellbeing.

Section three: Ten-item version of the Big Five Personality Inventory. ${ }^{36}$ The scale was designed to assess participants on five personality factors: Extraversion, Openness, Conscientiousness, Neuroticism and Agreeableness. Each factor was measured using two summed items.

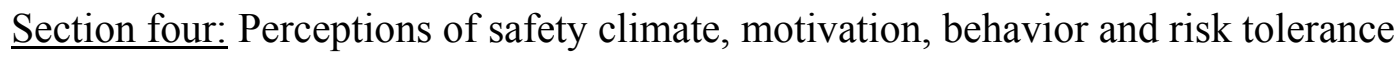
(three items per factor). ${ }^{37}$ Safety climate assessed the extent to which safety was valued on the farm, safety motivation assessed the extent to which farmers felt safety was an important 
part of their work, and safety compliance indicated the extent to which participants complied with safety regulations. Risk tolerance assessed the extent to which farmers were prepared to bend the rules, or take shortcuts to achieve performance targets.

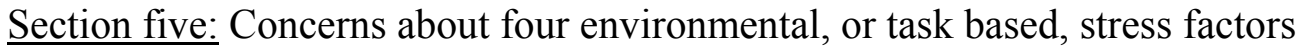
(stressors): workload, costs and profit margins, problems caused by weather or equipment and work-life imbalance. ${ }^{8}$

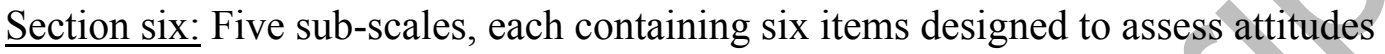
towards team based non-technical skills. The five sub-scales included were: Situation awareness, Teamwork and communication, Leadership, Task management and Decisionmaking. All items were derived from interviews conducted in an earlier study. ${ }^{19}$ The format and presentation of the items mirrored that of the TeamSTEPPS Teamwork Perceptions Questionnaire $\left(\mathrm{T}-\mathrm{TPQ}^{38}\right)$.

Section seven: Three sub-scales, each containing four items designed to assess attitudes to non-technical skills used while alone. The three sub-scales were: Situation awareness, Task management and Decision-making. As for section six, items were based on the format of the T-TPQ, and derived from the earlier interviews. ${ }^{19}$

\section{Data collection}

The questionnaire was web-based, constructed using SNAP software. Participants completed an electronic consent sheet, and then the questionnaire online, with data collection occurring via SNAP. Initial participants were contacted through organizations such as the National Farmer Union with the organizers sharing the e-mail invite with their members. Following that the invite letter was placed on social media (Facebook pages and groups) and shared through UK and Ireland based online farming forums. Further participants were recruited 
through the use of the snowball sampling technique, ${ }^{39}$ whereby each participant alerted friends and colleagues to the study.

\section{Analysis}

The majority of the defined scales used within the current questionnaire were designed to be assessed through the use of a scale score, or a sub-scale score, with items summed to create the measure. The first stage in the analysis was to sum the relevant items for both scales and sub-scales, then undertake diagnostic assessment to determine the skewness and kurtosis of each main variable. This was followed by an assessment of the internal consistency of each measure using Cronbach's alpha $(\alpha)$ which provides an indication of the level of relationship between the items for each measure (an alpha score of 0.7 or above is considered acceptable). Spearman correlation analysis was conducted to assess the associations between variables (Supplemental Table). Robust multiple regression analysis was conducted with each of the NTS sub-scales as criterion variables. Finally, to determine if there were differences across gender, level of training and farm type, ANOVA analysis was conducted. All analysis other than the robust regression analysis was conducted using SPSS, the robust regression was conducted using R.

\section{Results}

\section{Participant characteristics}

The majority of the sample was male and worked on farms with livestock. The level of agricultural training reported across participants varied from no training to training at postgraduate level, with the majority reporting training to certificate or diploma level (Table 1). The size of farm reported ranged widely; from 6 acres to 25000 acres (mean: 971.28 acres). 


\section{Diagnostics}

Preliminary analysis evaluated the skewness and kurtosis, alongside the central tendency of each of the main variables. Table 2 indicates that the majority of the main variables was skewed and had various levels of kurtosis, this finding impacted the analysis methods selected for statistical analysis in the next two sections.

Following initial diagnostics the internal consistency of each of the main measures was assessed using Cronbach's alpha $(\alpha)$. As illustrated by Table 2 all of the measures exhibited an acceptable or good level of internal consistency. ${ }^{40}$

\section{Correlation results}

To determine if there were associations between the measures, all 22 sub-scales plus experience (as defined by number of years' experience farming), were entered into a bivariate Spearman correlation analysis, as illustrated by Table 2. Farm size was included in this analysis initially, but had no significant $(p .>.05)$ associations with any of the other variables, and as such was removed from this and further analysis.

Farming experience positively correlates with team-based decision-making, task management and leadership. There was a negative correlation between farming experience and risk tolerance. Stress showed a negative correlation with team-based leadership, team task management, safety climate, and safety compliance. Stress was also positively correlated with concerns about workload, costs, equipment and work-life imbalance.

Neuroticism negatively correlated with team-based leadership, teamwork and communication, lone situation awareness, lone decision making, safety climate, and safety compliance. Neuroticism also positively correlated with concerns about costs, equipment, and work-life imbalance. Agreeableness correlated positively with safety climate and safety 
compliance. Conscientiousness correlated positively with team-based task management and teamwork, lone situation awareness, lone decision-making, and lone task management. Conscientiousness also correlated positively with safety climate and compliance.

Safety climate, motivation, and compliance showed a positive correlation across all sub-categories of non-technical skills, both team-based and lone-based skills. Safety motivation correlated positively with concerns about equipment problems. Risk tolerance showed a single negative correlation with team-based task management and lone decisionmaking.

\section{Robust regression analysis}

Due to the skewness and kurtosis of the criterion NTS variables, a robust regression analysis was conducted using the rlm function from the MASS package in R. The M-estimation was conducted using Huber weighting. ${ }^{41}$ Separate robust regression analyses were conducted for each of the eight non-technical skills ( $5 \mathrm{x}$ team, $3 \mathrm{x}$ lone). Each analysis included the following groups of predictor variables: individual characteristics (farming experience, personality traits, and stress), attitudes towards safety and risk (safety motivation, compliance, and climate, risk), concern about environmental stressors (workload, costs / profit, problems with equipment/infrastructure, and work-life imbalance). Table 3 illustrates the significant predictors (all excluded predictors were non-significant).

Across team-based NTS, safety motivation $(t=2.13, p<.001)$ significantly predicted attitudes concerning situation awareness in teams. Safety climate $(t=3.05, p<.001)$ significantly predicted attitudes towards leadership in farming teams. In terms of teamwork and communication safety climate $(t=2.80, p<.001)$, significantly predicted attitudes.

Concerns about costs and profits $(t=2.13, p<.001)$ significantly predicted attitudes towards 
task management. Finally concerns about costs and profits $(t=3.10, p<.001)$ significantly predicted attitudes towards team-based decision-making.

Neuroticism $(t=-2.02, p<.001)$ and conscientiousness $(t=2.53, p<.001)$ significantly predicted attitudes towards lone situation awareness. Conscientiousness $(t=$ 3.07, $p<.001)$ significantly predicted attitudes towards lone task management. Finally, neuroticism $(t=-3.47, p=.001)$, safety motivation $(t=2.35, p<.001)$ and concerns about costs and profits $(t=2.07, p<.001)$ predicted attitudes in lone decision-making.

\section{ANOVA analysis}

To determine whether the reported attitudes varied across team-based NTS sub-scales, gender, level of training (on job training versus external training), and type of farm (animals; crops; mixed) mixed measures ANOVA was conducted. The results indicate there was a significant difference in attitude across the five team-based NTS sub-scales $(\mathrm{F}(4,520)$ : 23.778, $\left.p<.001, \eta_{\mathrm{p}}{ }^{2}: .16\right)$. Pairwise comparisons using the Bonferroni correction indicated that attitudes towards situation awareness, leadership, teamwork and communication, and decision-making did not differ significantly from one another $(p .>.05)$, but were all significantly different (more positive) than attitudes towards task management $(p .<.05)$. There was no significant difference in attitude across gender $(p>.05)$, training category $(p>$ $.05)$ or farm purpose $(p>.05)$, nor were there any significant interactions.

The same analysis was then conducted for the lone NTS categories, the results mirrored those for the team-based NTS, with a significant difference in attitude across the three NTS sub-scales (F (2, 330): 29.27, $\left.p<.001, \eta_{\mathrm{p}}{ }^{2}: .15\right)$. Again pairwise comparisons using the Bonferroni correction indicated that attitudes towards situation awareness and decision-making did not differ significantly from one another $(p .>.05)$, but were significantly different (more positive) than attitudes towards task management $(p .<.05)$. There was no 
significant difference in attitude across gender $(p>.05)$, training category $(p>.05)$ or farm purpose $(p>.05)$, nor were there any significant interactions.

\section{Discussion}

The results of the current exploratory study begin to address the existing gap in the research regarding predictors of attitudes towards NTS. A range of individual characteristics, safety attitudes and environmental stressors were related to farmer NTS attitudes, showing support for the study hypotheses. The pattern of predictors varied across team-based and lone worker NTS. Personality factors neuroticism and conscientiousness were the primary predictors of lone worker NTS. In comparison alternative factors of safety climate, safety motivation and concerns about costs functioned as the main predictors for the team-based NTS.

The personality traits of neuroticism, conscientiousness, and agreeableness also show an association with elements of attitudes towards safety, replicating a previous study examining links between safety attitudes and personality in general industry. ${ }^{13}$ Finally, although there were no significant differences between groups regarding attitudes towards NTS, the results did indicate that task management appeared to be viewed more negatively than the remaining NTS, for both team and lone skills.

\section{Limitations}

This study is an exploratory study designed to take the first step in addressing the identified literature gap. As such the generalization of the results is restricted due to the limited sample size and focus on the UK and Ireland. Further research with farmers from additional regions is required. It should also be noted that the findings are based on self-report and as such may be susceptible to individual biases such as social desirability bias. A gender imbalance is present in the sample, with the majority of the participants being male; although, this is 
somewhat representative of UK farming population. ${ }^{1}$ Finally, this study had the capacity to address NTS attitudes only; further research is required to assess the impact of the characteristics reported here on actual NTS performance.

\section{Team NTS}

Endsley ${ }^{42}$ defines situation awareness as comprised of three non-linear levels; perception, understanding and anticipation. Team-based situation awareness is the extent to which each member of a team possesses adequate, and shared, situation awareness. The current findings suggest high levels of reported safety motivation predict high levels of reported team situation awareness, and team situation awareness was positively associated with safety climate, safety motivation, and safety compliance. This link between situation awareness and safety attitudes has been reported in other industries including shipping ${ }^{15}$ and production, ${ }^{43}$ with the suggestion that unsafe work behaviors may be linked to failures in awareness, rather than intentional violations. Alternatively, individuals who take shortcuts or violate the rules on a regular basis may simply be more likely to ignore their work environment. ${ }^{15}$ The current study builds on those findings, with the suggestion that farmers who consider safety an important element of their work are more likely to maintain an awareness of their surroundings.

The perception of safety climate by individuals encompasses consideration of general practices and procedures relevant to safety in the workplace. ${ }^{10}$ Safety climate has been shown to be linked to safety behaviors at both the individual and group level. ${ }^{10,44}$ The current results indicate that safety climate functions as a significant predictor of farmer attitudes towards teamwork and leadership, with safety motivation and compliance also positively associated with both NTS. Research suggests that this relationship could be due to the leader or supervisor of a team establishing the team safety climate by sharing their expectations of 
safety behaviors, such as adhering to safety protocols or wearing safety equipment. ${ }^{44}$ This can generate a shared team approach to safety, where a positive approach will lead to enhanced levels of safety. ${ }^{44}$ It is also interesting to note that the current findings indicate a negative association between neuroticism, teamwork and leadership attitudes, this may be due to the link between neuroticism and strained interpersonal relationships. ${ }^{10}$

The development of routines and the importance of planning ahead have been identified as methods of mitigating risk and coping with stress in agriculture. ${ }^{9,22}$ This is supported within the current study with a negative association between team task management, stress, and risk tolerance. The current results also indicate that concern about farming costs functions as a predictor of team-based task management and decision-making. This is perhaps unsurprising given that previous research indicates that financial worries are a major stressor for farmers, ${ }^{9}$ with many using a problem-solving or task management orientation as a coping response. ${ }^{9}$ It should be noted that this primarily referred to principal farmers with a managerial role. The current study did not differentiate between farm owners and workers, so the current result may be due to a majority of owner farmers within the sample. Moreover, the relatively negative attitudes towards team- and lone task management may suggest that this is a skill that would benefit from further support within agriculture.

\section{Lone NTS}

A lone worker is an individual who works alone, without direct supervision, on a regular or occasional basis. ${ }^{5}$ Working alone is associated with several risks, with the most relevant for agriculture being the prospect of accident or injury. ${ }^{45}$ Unfortunately, despite farmers being aware of the risk inherent in working alone, it is often a necessity due to a lack of personnel. ${ }^{22}$ It is important to identify ways of mitigating the risk of lone working, including the consideration of the training and development of NTS as a possible avenue. 
The current study indicates that neuroticism and conscientiousness were significant predictors of lone worker NTS attitudes. The link between task management and conscientiousness is perhaps unsurprising given that conscientious individuals have been reported as achievement focused, with an inherent desire to complete tasks on time, whilst following procedures. ${ }^{46}$ Similarly, individuals low in neuroticism are less likely to be distracted and are more task focused than individuals high in neuroticism, ${ }^{46}$ which may explain the negative association between neuroticism, situation awareness and decisionmaking. Previous researchers have suggested that results such as these could be used to inform staffing decisions on the basis of personality traits; ${ }^{34}$ however, given the unique nature of farming, where many farmers work alone, selecting employees on the basis of personality might not be practical.

An alternative possibility is to consider the potential impact of these traits on NTS training effectiveness. This is particularly important given past research suggesting that training based on NTS may be rejected by a proportion of the population and effectiveness can vary across organizations. ${ }^{47}$ The authors suggest NTS training should be tailored to each organization or workgroup, which can be done through surveying the target group and using the resultant data to develop the training intervention. ${ }^{47}$ The consideration of individual and environmental factors should enable further specification of training, enhancing its effectiveness. The development of such training programs could enhance safety and reduce injury in agriculture, as has been indicated in other domains. ${ }^{48}$

\section{Conclusion and Implications}

There are two main implications suggested by this data; First, individual and environmental factors appear to be related to NTS attitudes, and may therefore function as antecedents for NTS behaviors in agriculture. Second, this result might influence the development of future 
NTS training programs within agriculture. To be effective future training programs may need to consider the impact of individual and environmental characteristics on NTS behaviors and attempt to compensate for this variation by producing tailored training interventions.

\section{References}

1. Health and Safety Executive (HSE). Health and Safety in Agriculture, Forestry and Fishing in Great Britain, 2014/15. 2015; Health and Safety Executive, London, UK.

2. Douphrate DI, Stallones L, Lostrup CL, Nonnenmann MW, Pinzke S, Hagevoort GR, Lundqvist P, Jakob M, Xiang H, Xue L, Jarvie P, McCurdy SA, Reed S, Lower T. Workrelated injuries and fatalities on dairy farm operations - a global perspective. $J$ Agromedicine. 2013;18:256-264.

3. Rautiainen RH, Reynolds SJ. Mortality and morbidity in agriculture in the United States. $J$ Agric Saf Health.2002;8:259-276.

4. Mitloehner FM, Calvo,MS. Worker health and safety in concentrated feeding operations. $J$ Agric Saf Health. 2008; 14:163-187.

5. HSE. Working alone: Health and safety guidance on the risks of lone working. 2013; Health and Safety Executive, London, UK.

6. Hagel L, King N, Dosman JA, Lawson J, Trask C, Pickett W. Profiling the safety environment on Saskatchewan farms. Safety Sci. 2016;82:103-110.

7. Thu KT, Lasley P, Whitten P, Lewis M, Donham KJ, Zwerling C, Scarth R. Stress as a risk factor for agricultural injuries. J Agromedicine. 1997;4:181-191.

8. Glasscock DJ, Rasmussen K, Cartensen O, Hansen ON. Psychosocial factors and safety behaviour as predictors of accidental work injuries in farming. Work and Stress. 2006;20:173-189. 
9. HSE. Farmers, Farm workers and Work-Related Stress. 2005; Health and Safety Executive, London, UK.

10. Neal A, Griffin MA. A study of lagged relationships among safety climate, safety motivation, safety behaviour, and accidents at the individual and group levels. $J$ Appl Psychol. 2006;91:946-953.

11. Rundmo T. Associations between risk perception and safety. Safety Sci. 1996;24:197-209.

12. Sneddon A, Mearns K, Flin R. Stress, fatigue, situation awareness and safety in offshore drilling crews. Safety Sci. 2013;56:80-88.

13. Henning JB, Stufft CJ, Payne SC, Bergman ME, Mannan MS, Keren N. The influence of individual differences on organizational safety attitudes. Safety Sci. 2009;47:337-345.

14. Flin R, O'Connor P, Crichton M. Safety at the Sharp End: A Guide to Non-Technical Skills. Ashgate, Farnham: 2008.

15. Sneddon A, Mearns K, Flin R. Safety and situation awareness in offshore crews. Cognition, Technology \& Work. 2006;8:255-267.

16. Reader T, O’Connor P. The Deepwater Horizon explosion: non-technical skills, safety culture, and system complexity. Journal of Risk Research. 2014;17:405-424.

17. Fletcher G, Flin R, McGeorge P, Glavin R. Anaesthetists non-technical skills (ANTS): evaluation of a behavioural marker system. Br J Anaesth. 2003;90:580-588.

18. Mitchell L, Flin R, Yule S, Mitchell J, Coutts K, Youngson G. Thinking ahead of the surgeon: an interview study to identify scrub nurses' non-technical skills. Int J Nurs Stud. 2011;48:818-828.

19. Irwin A, Poots J. The human factor in agriculture: an interview study to identify farmers' non-technical skills. Safety Sci. 2015;74:114-121. 
20. Voaklander DC, Hartling L, Pickett W, Dimich-Ward H, Brison RJ. Work-related mortality among older farmers in Canada. Can Fam Physician. 1999;45:2903-2910.

21. Farmar-Bowers Q, Lane R. Understanding farmers' strategic decision-making processes and the implications for biodiversity conservation policy. J Environ Manage. 2009;90:1135-1144.

22. Lindahl C, Lundqvist P, Norberg AL. Swedish dairy farmers' perceptions of animalrelated injuries. J Agromedicine. 2012;17:364-376.

23. Neal A, Griffin MA. Perceptions of safety at work: Developing a model to link organizational safety climate and individual behavior. 1997; 12th Ann Conf Society Ind Organ Psych, St. Louis, MO: Apr.

24. Lindahl C, Pinzk, S, Keeling LJ, Lundqvist P. The effect of stress, attitudes and behaviour on safety during animal handling in Swedish dairy farming. J Agric Saf Health. 2015;21:13-34.

25. Hagel L, Pahwa P, Dosman JA, Pickett W. Economic worry and the presence of safety hazards on farms. Accid Anal Prev. 2013;53:156-160.

26. Karttunen JP, Rautiainen RH. Occupational injury and disease incidence and risk factors in Finnish agriculture based on 5-year insurance records. J Agromedicine. 2013;18:50-64.

27. Sprung JM, Britton AR. The dyadic context of safety: An examination of safety motivation, behaviour, and life satisfaction among farm couples. Safety Sci. 2016;85:1-8.

28. Watson D, Clark LA. Extraversion and its positive emotional core. In: Hogan R, Johnson J, Briggs S, eds. Handbook of Personality Psychology. San Diego: Academic Press; 1997. 767-793.

29. DeJoy DM, Searcy CA, Murphy LR, Gershon RR. Behavioral-diagnostic analysis of compliance with universal precautions among nurses. J Occup Health Psychol. 2000;5:127-141. 
30. Clarke S, Robertson IT. A meta-analytic review of the big five personality factors and accident involvement in occupational and non-occupational settings. Journal of Occupational and Organizational Psychology. 2005;78:355-376.

31. Buck MA. Proactive personality and Big Five traits in supervisors and workgroup members: Effects on safety climate and safety motivation. (Unpublished doctoral dissertation). 2011; Portland State University, Portland, OR.

32. McCrae RR, Costa PT. Updating Norman's 'Adequate Taxonomy': Intelligence and personality dimensions in natural language and in questionnaires. J Pers Soc Psychol. $1985 ; 49: 710-721$.

33. Wallace JC, Vodanovich SJ. Workplace safety performance: Conscientiousness, cognitive failure, and their interaction. J Occup Health Psychol 2003;8:316-327.

34. Beus JM, Dhanani LY, McCord MA. A meta-analysis of personality and workplace safety: Addressing unanswered questions. J Appl Psychol. 2015;100:481-498.

35. Goldberg DP, Hillier VF. A scaled version of the general health questionnaire. Psychol Med. 1979;9:139-145.

36. Rammstedt B, John OP. Measuring personality in one minute or less: A 10-item short version of the Big Five Inventory in English and German. Journal of Research in Personality. 2007;203-212.

37. Neal A, Griffin MA, Hart PM. The impact of organizational climate on safety climate and individual behavior. Safety Sci. 2000;34:99-109.

38. Battles J. TeamSTEPPS Teamwork Perceptions Questionnaire (T-TPQ) Manual. Washington, DC: American Institutes for Research; 2010.

39. Goodman LA. Comment on respondent driven sampling and snowball sampling in hard to reach populations and snowball sampling in not hard to reach populations. Sociological Methodology. 2011;41:347-353. 
40. George D, Mallery P. SPSS for Windows step by step: A simple guide and reference. 11.0 update (4th edition). Boston: Allyn and Bacon; 2003.

41. Huber PJ. Robust regression: asymptotics, conjectures and Monte Carlo. Annals of Statistics. 1973;799-821.

42. Endsley MR. Toward a theory of situation awareness in dynamic systems. Human Factors. 1995;37:32-64.

43. Wallace JC, Vodanovich SJ. Workplace safety performance: conscientiousness, cognitive failure, and their interaction. J Occup Health Psychol. 2003;8:316-327.

44. Huang Y, Zohar D, Robertson MM, Garabet A, Lee J, Murphy LA. Development and validation of safety climate scales for mobile remote workers using utility/electrical workers as an exemplar. Accid Anal Prev. Traffic Psy Behav; 2013;59:76-86.

45. Kapp EA. The influence of supervisor leadership practices and perceived group safety climate on employee safety performance. Safety Science. 2012;50:1119-1124.

46. Barrick MR, Mount MK, Li N. The theory of purposeful work behaviour: the role of personality, higher order goals, and job characteristics. Academy of Management Review. 2013;38:132-153.

47. Helmreich RL, Merritt AC, Wilhelm JA. The evolution of crew resource management training in commercial aviation. Int J Aviat Psychol. 1999;9:19-32.

48. Flin R, Patey R. Improving patient safety through training in non-technical skills. $B M J$. 2009;339:b3595. 
Table 1: Participant characteristics (mean or frequency).

\begin{tabular}{llll}
\hline Personal characteristic & Category & Mean $(\mathrm{sd})$ & Frequency (\%) \\
\hline Gender & Male & $136(81)$ \\
Age & Female & $32(19)$ \\
Years of farming & & $43.08(14.6)$ & \\
experience & $25.8(14.1)$ & \\
Training level & None & & $13(7.6)$ \\
& On farm training & $44(25.9)$ \\
& Certificate / diploma & $65(38.2)$ \\
& Undergraduate & $46(27.1)$ \\
& degree & $2(1.2)$ \\
Farm purpose & Postgraduate & & $100(58.8)$ \\
& degree & $25(14.7)$ \\
Farm size (acres) & Animals & & $45(26.5)$ \\
\hline
\end{tabular}


Table 2: Scale reliability analysis using Cronbach's Alpha $(\alpha)$, for each of the four main measures, and associated sub-scales, used within the current questionnaire study.

\begin{tabular}{|c|c|c|c|c|c|c|c|c|}
\hline Measure & $\begin{array}{l}\text { Number of } \\
\text { items }\end{array}$ & $\begin{array}{l}\text { Minimum - } \\
\text { Maximum }\end{array}$ & $\begin{array}{l}\text { Scale } \\
\text { mean }\end{array}$ & $\begin{array}{l}\text { Scale } \\
\text { Median }\end{array}$ & SD & $\alpha$ & Skewness & Kurtosis \\
\hline $\begin{array}{l}\text { Stress (General } \\
\text { health) }\end{array}$ & 5 & $5-25$ & 11.55 & 11.00 & 2.51 & 0.79 & .86 & 1.16 \\
\hline \multicolumn{9}{|l|}{ Safety \& Risk } \\
\hline Safety climate & 3 & $3-16$ & 11.16 & 12.00 & 2.48 & 0.87 & -.45 & .07 \\
\hline Safety motivation & 3 & $3-16$ & 12.17 & 12.00 & 1.83 & 0.78 & -.49 & .20 \\
\hline Safety compliance & 3 & $3-16$ & 10.35 & 10.00 & 2.38 & 0.85 & -.19 & -.41 \\
\hline Risk & 3 & $3-16$ & 9.27 & 9.00 & 2.15 & 0.70 & -.04 & .13 \\
\hline \multicolumn{9}{|c|}{ Environmental stressors } \\
\hline Workload & 3 & $3-15$ & 8.57 & 9.00 & 1.89 & 0.71 & -.23 & .28 \\
\hline Costs / profit & 5 & $5-25$ & 15.03 & 15.00 & 3.32 & 0.84 & -.56 & .08 \\
\hline $\begin{array}{l}\text { Equipment / } \\
\text { infrastructure } \\
\text { problems }\end{array}$ & 6 & $6-30$ & 15.75 & 15.00 & 3.46 & 0.78 & & 13 \\
\hline $\begin{array}{l}\text { Work-life } \\
\text { imbalance }\end{array}$ & 3 & $3-15$ & 7.53 & 8.00 & 2.16 & 0.70 & $\gamma$ & -.39 \\
\hline \multicolumn{9}{|l|}{ Team NTS } \\
\hline $\begin{array}{l}\text { Situation } \\
\text { awareness }\end{array}$ & 6 & $6-30$ & 22.01 & 23.00 & 3.64 & 0.85 & -.91 & 2.55 \\
\hline $\begin{array}{l}\text { Teamwork and } \\
\text { communication }\end{array}$ & 6 & $6-30$ & 22.86 & 24.00 & 25 & 0.93 & -.96 & 2.30 \\
\hline Leadership & 6 & $6-30$ & 22.03 & 23.00 & 4.27 & 0.91 & -.62 & .91 \\
\hline Task management & 6 & $6-30$ & 20.08 & 20.00 & 3.73 & 0.81 & -.30 & .53 \\
\hline Decision-making & 6 & $6-30$ & 22.28 & 23.00 & 3.74 & 0.88 & -.80 & 2.14 \\
\hline \multicolumn{9}{|l|}{ Lone NTS } \\
\hline $\begin{array}{l}\text { Situation } \\
\text { awareness }\end{array}$ & 4 & $4-20$ & 16.37 & & 1.97 & 0.79 & -.14 & 1.58 \\
\hline Task management & 4 & $4-20$ & 15.23 & 16.00 & 2.48 & 0.76 & -.26 & .12 \\
\hline Decision-making & 4 & $4-20$ & 15.99 & 16.00 & 2.16 & 0.70 & -.08 & .13 \\
\hline
\end{tabular}


Table 3: Robust regression analysis for the prediction of attitudes towards non-technical skills (team and lone), only significant predictors shown. Significance level set at $p<.01$.

\begin{tabular}{llll}
\hline Criterion variable & Predictor variable(s) & $\begin{array}{l}\text { Coefficient Value } \\
\text { (standard error) }\end{array}$ & $t$ value \\
\hline Team NTS & Safety motivation & $0.53(0.25)$ & 2.13 \\
$\quad$ Situation awareness & Safety climate & $0.64(0.21)$ & 3.05 \\
Leadership & Safety climate & $0.63(0.22)$ & 2.80 \\
Teamwork & Costs & $0.23(0.10)$ & 2.13 \\
Task management & Costs & $0.34(0.11)$ & 3.10 \\
$\begin{array}{l}\text { Decision-making } \\
\text { Lone NTS }\end{array}$ & Neuroticism & $-0.20(0.10)$ & -2.02 \\
Situation awareness (lone) & Conscientiousness & $0.28(0.11)$ & 2.53 \\
Task management (lone) & Conscientiousness & $0.40(0.13)$ & 3.07 \\
& Neuroticism & $-0.32(0.09)$ & -3.47 \\
Decision-making (lone) & Safety motivation & $0.31(0.13)$ & 2.35 \\
& Costs & $0.11(0.05)$ & 2.07 \\
\hline
\end{tabular}

